ISSN 1518-3483

Licenciado sob uma Licença Creative Commons

\title{
Relação pedagógica no grupo tutorial: desafios e possibilidades das metodologias participativas (ativas)
}

\section{Pedagogical relationship the Group tutorial: challenges and possibilities of participative methodologies (active)}

\section{Edileuza Fernandes da Silva*}

Faculdade de Educação (UnB), Brasília, DF, Brasil

\section{Resumo}

Este texto objetiva analisar a relação pedagógica desenvolvida no grupo tutorial na metodologia PBL adotada no curso de Medicina de um centro universitário privado do Distrito Federal, visando compreender desafios e possibilidades na construção do conhecimento de forma colaborativa e participativa. Colaboraram com a pesquisa um professor e quatro estudantes do segundo semestre do curso. A abordagem metodológica consistiu na análise de depoimentos levantados por meio de entrevista semiestruturada com professor, grupo focal com quatro estudantes e observação de oito horas de sessões tutoriais que oportunizaram compreender aspectos relativos à dinâmica do grupo tutorial. O quadro teórico da pesquisa foi elaborado com base em Berbel (1998), Leitinho e Sá Carneiro (2013) para discutir a

* EFS: Doutora em Educação, e-mail: edileuzafe.unb@gmail.com 
Aprendizagem Baseada em Problemas; em Veiga $(2001,2014)$ para discutir a relação pedagógica e o processo didático; em Saviani $(2007,2008)$ para abordar a pedagogia histórico-crítica; e em Araújo (2017) para discutir as matrizes pedagógico-metodológicas ativas e participativas. Da análise dos dados da pesquisa, foi possível apreender que no grupo tutorial, a relação pedagógica é democrática, pautada no respeito ao indivíduo, sendo o poder de decisão e ação compartilhado por todos e identificar alguns elementos constitutivos do grupo tutorial que sinalizam o movimento de transição da metodologia ativa para a pedagogia histórico-crítica. A formação médica requer metodologia colaborativa, participativa e problematizadora fundamentada na prática social em que professor e estudantes, apesar de ocuparem posições distintas, constroem uma relação pedagógica favorável à compreensão e ao encaminhamento de soluções dos problemas apresentados pela prática social.

Palavras-chave: Relação pedagógica. Grupo tutorial. Metodologias participativas.

\section{Abstract}

This text aims to analyse the pedagogical relationship developed in the Group on the methodology adopted in the PBL tutorial course of Medicine from a private University Center of Distrito Federal, in order to understand challenges and possibilities in the construction of knowledge collaboratively and participatory. Cooperated with the searches for a teacher and four students of the second half of the course. The methodological approach consisted in analyzing evidence collected through semi-structured interview with professor, focal group with four students and 8 hour session watching tutorials that nurture understanding aspects of group dynamics tutorial. The theoretical framework of research was based on Berbel (1998), Leitinho and Sá Carneiro (2013) to discuss the problem-based learning; in Veiga $(2001,2014)$ to discuss the pedagogical relationship and the didactic process; in Saviani $(2007,2008)$ to address the historic-critical pedagogy; and in Araújo (2017) to discuss the pedagogical-methodological arrays active and participatory. The analysis of the survey data, it was possible to learn who in the Group tutorial, the pedagogical relationship is democratic, based on respect for the individual, and the power of decision and action shared by all and identify some elements constituting the Group tutorial that signal the movement of transition from active methodology to historical-critical pedagogy. The medical training requires collaborative, participatory methodology and problem based on social practice in which teacher and students, although distinct positions, build a occupied 
relationship conducive to pedagogical understanding and the movement of solutions of the problems presented by social practice.

Keywords: Pedagogic relationship. Group tutorial. Participatory methodologies.

\section{Introdução}

O contexto social e profissional atual tem demandado das instituições de ensino superior (IES) a formação de profissionais com responsabilidade social, compromisso político com a defesa da cidadania e da dignidade humana e competência técnica para atender às necessidades da população nas diferentes esferas de trabalho. No campo da saúde, por exemplo, a formação do profissional médico deve voltar-se para os diferentes níveis de atenção à saúde, com ações de promoção, prevenção, recuperação e reabilitação da saúde, nos âmbitos individual e coletivo (CNE/CES, n. 3, 2014). Nesse sentido, a Medicina deixa de ser uma prática elitista, hospitalocêntrica, desvinculada do contexto social e das políticas públicas emanadas do poder central, e volta-se às práticas sociais dos diversos segmentos da sociedade com base nas políticas públicas de saúde, considerando os aspectos ético-sociais e humanísticos da profissão.

Assim, as exigências de um novo perfil profissional do médico indicam quão complexa é a sua formação e reforçam a importância das Instituições de Ensino Superior (IES) assumirem em seus currículos a perspectiva integrada de formação que visa à prevenção e à resolução de problemas do cotidiano da saúde individual e coletiva; adotarem metodologias que rompam com processos conservadores de ensino-aprendizagem, pautados na transmissão-recepção de conteúdos técnico-científicos; e investimento na formação continuada dos professores como eixo do projeto pedagógico do curso.

Diante dessa realidade e, com o intuito de contribuir para o debate acerca das metodologias no ensino superior, este texto relata parte 
de um estudo mais amplo a respeito da docência universitária o qual visa compreender a relação pedagógica desenvolvida em sete cursos de graduação de um centro universitário privado do DF. O objetivo da discussão ora proposta é analisar a relação pedagógica no grupo tutorial, técnica de ensino adotada no curso de Medicina no âmbito da metodologia de Aprendizagem Baseada em Problemas (PBL), seus desafios e suas possibilidades na construção do conhecimento de forma colaborativa e participativa.

A metodologia PBL tem fundamentado cursos de formação médica há mais de 50 anos em universidades de países como Canadá, Holanda e Estados Unidos, e, recentemente, na América Latina. No Brasil a adesão à metodologia tem ocorrido na área da saúde, especificamente nos cursos de Medicina, como resposta à insatisfação dos estudantes diante da quantidade de conhecimentos considerados irrelevantes à prática médica (BARROWS, 1999). Alinhada a essa perspectiva, as Diretrizes Curriculares Nacionais do Curso de Graduação em Medicina (DCNs, 2014) indicam, para os cursos de formação médica, a aplicação de metodologias que privilegiem a participação ativa do estudante na construção do conhecimento e na integração entre os conteúdos, o que assegura a indissociabilidade entre ensino, pesquisa e extensão.

A opção pela abordagem qualitativa de pesquisa fundamentou-se no pressuposto de que não é possível submeter dados gerados em contextos sociais de relações e interações a um esquema simplificador e objetivo de análise, sob o risco de prejudicar a compreensão acurada da realidade determinada social, econômica, cultural e histórica. Como procedimentos para levantar os dados, adotou-se a entrevista semiestruturada com o professor do módulo Mecanismos de Agressão e Defesa ministrado no segundo semestre do curso de Medicina, conjugada com a realização de um grupo focal composto por quatro estudantes e com a observação de oito horas de sessões tutoriais, mediados pelo professor Henrique ${ }^{1}$, as quais oportunizaram apreender aspectos relativos à dinâmica do grupo

1 Serão usados pseudônimos na indicação dos nomes dos participantes da pesquisa para preservação de suas identidades. 
tutorial voltados ao objetivo deste estudo. Na IES há salas específicas para o tutorial, em formato retangular com quadros brancos nas paredes laterais e na parede frontal e mesa retangular ao centro, em torno da qual se reuniam 10 estudantes e o professor sentado em uma das extremidades.

Houve orientações para que, durante o grupo tutorial, os estudantes não utilizassem recursos tecnológicos, como computadores e aparelhos móveis, com o objetivo de evitar pesquisas acerca do problema em estudo. Procurou-se privilegiar os saberes prévios dos estudantes, pois suas práticas sociais são as referências básicas no processo inicial de discussão do problema, levantamento de questões e formulação de objetivos de aprendizagem.

\section{O grupo tutorial, técnica de ensino no âmbito da metodologia PBL}

A PBL é alternativa pedagógica e metodológica de ensino-aprendizagem que mobiliza os estudantes a construírem conhecimentos a partir de problemas, desenvolvendo de forma autônoma e criativa a capacidade de reflexão na ação e de comunicação como subsídio à busca de soluções para problemas práticos da vida acadêmica e escolar de diferentes áreas de conhecimento (LEITINHO; SÁ CARNEIRO 2013, p. 99).

Ao adotar a PBL como metodologia no curso de Medicina, a IES pesquisada expressa a compreensão de que os conhecimentos técnico-científicos da área médica devem resultar de um processo que articule saberes globais e locais, teoria-prática, ensino-pesquisa, professor-aluno, formação-trabalho. É uma visão epistemológica que requer a abertura da cultura erudita predominante nos currículos de formação profissional na educação superior às culturas locais e às situações-problemas reais que emergem do contexto concreto de trabalho de determinado campo científico, o que contribui para a constituição de relações entre os diferentes tipos de conhecimentos e destes com as questões que emergem do campo concreto de atuação profissional. Ao assumir esta postura epistemológica, a IES propõe Metodologia Ativa (PBL) para o curso de Medicina; vislumbra perspectivas 
formativas que privilegiem as discussões, os questionamentos acerca da racionalidade da ciência normativa e conservadora; e busca romper com a fragmentação do conhecimento, predispondo os estudantes à indagação, à emancipação e à autonomia acadêmica (SANTOS, 1996).

$\mathrm{Na}$ metodologia PBL, incluem-se diversificadas atividades acadêmicas, como conferências, prática profissional, aulas de laboratórios, sessões de simulação e grupo tutorial. Este último é composto de 8 a 10 estudantes e um professor que assume sua aplicação em uma carga horária em torno de 4 (quatro) horas aulas para o estudo de cada problema elaborado previamente por comissão de docentes do curso. Seu desenvolvimento no ensino superior segue sete etapas identificadas por Berbel (1998):

1) Leitura do problema a ser estudado, identificação e esclarecimento de termos, palavras e expressões desconhecidas;

2) identificação dos problemas propostos pelo enunciado;

3) formulação de hipóteses explicativas para os problemas identificados na etapa anterior;

4) resumo das hipóteses;

5) formulação dos objetivos de aprendizagem (sistematização do que os estudantes deverão estudar para aprofundar os conhecimentos formulados nas hipóteses explicativas, a partir de seus saberes prévios);

6) estudo individual dos assuntos levantados nos objetivos de aprendizagem; e,

7) retorno ao grupo tutorial para rediscussão do problema frente aos novos conhecimentos adquiridos na etapa de estudo anterior.

\section{As perspectivas do professor e dos estudantes acerca do grupo tutorial na PBL}

Os dados levantados por meio da entrevista com o professor Henrique, do grupo focal realizado com os estudantes e das observações 
dos tutoriais serão analisados neste tópico para situar o papel do grupo tutorial na metodologia PBL e suas implicações na relação pedagógica professor-aluno, tomando por base ser ela influenciada pelos pressupostos teórico-metodológicos do currículo do curso de Medicina e implementados pelo professor. Nessa perspectiva, o trabalho pedagógico desenvolvido no grupo tutorial pelo docente e pelos estudantes contribui para concretizar os objetivos e as intencionalidades do projeto pedagógico da instituição e do curso.

O professor Henrique, participante da pesquisa, desenvolve no curso o módulo de Saúde Coletiva e a condução do grupo tutorial, que, em sua visão, é a técnica principal da PBL na construção do conhecimento por possibilitar

[...], transformar a lógica do professor protagonista do processo de ensino-aprendizagem e ver que o aluno é protagonista também. Os alunos têm no início do curso muita parte teórica, então a tutoria conduz para aspectos importantes a serem discutidos, articulando o conhecimento prático e o conhecimento teórico sobre o assunto. [...], ajustando a condução para se chegar ao objetivo desejado (Professor Henrique).

Ao referir-se ao grupo tutorial como técnica predominante da PBL, o professor destaca o protagonismo do estudante na construção do conhecimento em um processo de interação entre sujeito (aluno em atividade) e objetos dos conhecimentos (diferentes saberes), sob a orientação do professor, também protagonista, que organiza e conduz a ação do sujeito diante do objeto, articula teoria e prática e "ajusta a condução" para o alcance dos objetivos de aprendizagem definidos pelos estudantes na primeira sessão do tutorial. Nessa visão, o estudante assume protagonismo por ser considerado sujeito da aprendizagem e, consequentemente, sua atividade cognitivo-afetiva é fundamental para manter uma relação interativa com o objeto do conhecimento (VEIGA, 2001, p. 147); isso favorece o alcance dos objetivos de aprendizagem, sem prescindir do papel mediador do professor. 
Nas narrativas dos estudantes, há destaques para aspectos da relação professor-aluno construída no grupo tutorial que a diferencia da relação predominante na aula tradicional: "é importante ressaltar que quando estamos com um professor dando aula, é uma relação muito vertical" (Diogo); "no grupo tutorial, o professor não pode chegar e falar: 'olha, vou ensinar isso pra vocês', porque isso não é o método" (Janaína). O estudante Diogo reconhece a posição magistrocêntrica do professor, aquele que "dá aula”, em alusão ao caráter transmissivo predominante na aula e verticalizado da relação pedagógica no ensino superior; enquanto a estudante Janaína, ressalta a centralidade no professor transmissor de conteúdos como um aspecto que pode descaracterizar a metodologia PBL.

O grupo tutorial, no âmbito da PBL, é desenvolvido com base na ideia de que o processo de ensino-aprendizagem constitui-se ato de problematizar e compreender a realidade em estudo, a partir da prática social dos estudantes, que são mobilizados pelos professores para discutirem situações-problemas dos campos científicos privilegiados na formação. A perspectiva do tutorial é de constituição de uma relação pedagógica que rompe com a forte intervenção do professor e com a passividade dos estudantes, características da aula fundamentada em matriz pedagógico-metodológica de ensino tradicional. Destaca-se que a prática social dos estudantes é fundamental na realização do tutorial, porque põe-se como o ponto de partida e o ponto de chegada do processo de construção do conhecimento (SAVIANI, 2008), transformada e orientada pelas/pelos questões/objetivos de aprendizagem e de referenciais teóricos do campo científico da Medicina.

Foi possível apreender ainda, das narrativas dos estudantes, que o professor no grupo tutorial, ao conferir centralidade ao aluno, de certa forma, abre mão do seu protagonismo, nesse caso, "o aprendente seria o carro-chefe em detrimento do ensinante, ou ainda, o puerocentrismo substituiria o magistrocentrismo" (ARAÚJO, 2017, p. 10). Essa perspectiva parece não atender às expectativas de formação dos estudantes, como relata Diogo, ao ser questionado pela pesquisadora se a interferência do professor romperia com a ideia do protagonismo discente defendida na PBL: "ele não está impondo o conteúdo, não estamos passivos, estamos 
querendo esclarecer melhor as ideias previamente estudadas". O estudante manifesta a preocupação com a pouca intervenção do professor durante o grupo tutorial e com a forma como sua ausência pode comprometer o alcance dos objetivos de aprendizagem e, consequentemente, a construção de conhecimentos, visão esta corroborada por outros estudantes:

[...] uma dificuldade do tutorial é que na hora de montar os objetivos, se não tiver o cuidado, pode ficar ou uma coisa muito ampla, ou uma coisa muito superficial (Pietra).

É, mas vai variar a profundidade que teremos, porque já aconteceu com a gente. Fizemos um objetivo, aí o tutor acabou passando despercebido, a gente não abordou na profundidade o que deveria ter sido abordado. É o que a gente chama, lacuna do tutorial (Pedro).

Percebe-se pelas falas dos estudantes certo desencontro entre o que o professor expressou por meio da entrevista em relação ao seu papel mediador no grupo tutorial e as manifestações dos estudantes acerca de sua pouca intervenção, o que suscitou algumas questões acerca da relação entre ambos na condução do tutorial que são: Como contemplar a ação do professor e do estudante na relação pedagógica que se desenvolve no grupo tutorial sem sobreposição de papéis, sem polarização e sem omissão? Como dá centralidade aos estudantes e às aprendizagens sem secundarizar o ensino e a ação mediadora do professor? Como desenvolver metodologias no ensino superior que conciliem o ensinar e o aprender, o professor e o aluno numa relação colaborativa, dialógica e dialética?

Ao procurar assumir os pressupostos teórico-metodológicos da PBL, o professor Henrique se deparou com alguns desafios:

O primeiro desafio é ajudar a conduzir para que os objetivos de aprendizagem sejam alcançados por todos sem a intervenção direta do professor, permitindo que os conceitos saíam do grupo.

O segundo desafio é controlar a ansiedade dos alunos, no sentido de esperarem respostas do professor. Eles sempre esperam que o professor chegue ao final e faça a sintese do conhecimento. Fazê-los compreender que ficou 
uma lacuna, mas também fazê-los perceberem, ao final do tutorial, nada de importante foi deixado de ser discutido e que algumas coisas não foram bem discutidas.

O terceiro desafio é incentivar todos a participarem, o que é diferente para cada grupo, embora todos tenham que coordenar o grupo tutorial. Mas ainda acho que alguns alunos têm timidez muito grande, o que interfere no desenvolvimento do método (Professor Henrique).

A relação professor-aluno é condição para que o processo didático - ensinar, aprender, pesquisar e avaliar - ocorra como encontro dialógico com as presenças de sujeitos singulares que trazem para o espaço onde se desenvolve, sala de aula convencional ou não, saberes, experiências, culturas, valores e crenças que significam esse processo e nele são ressignificados. Os desafios indicados pelo professor de conduzir o tutorial sem intervenção direta, controlar a ansiedade dos alunos pelas respostas do professor e incentivar a participação de todos revelam o conflito epistemológico e metodológico por ele vivido no desenvolvimento da PBL de matriz pedagógico-metodológica ativa (escolanovista), cuja centralidade no aluno e na aprendizagem secundariza o papel do professor e do ensino. Nessa conflitualidade o professor questiona:

será que os alunos teriam o mesmo desempenho, se não tivessem tutor e tivessem de estudar por conta própria? Acho que não, essa relação é construtiva, ter o professor para conduzir, observar, facilita o processo, dá um direcionamento melhor (Professor Henrique).

De acordo com Santos (1996), "uma educação que parte da conflitualidade dos conhecimentos visará, em última instância, conduzir à conflitualidade entre sensos comuns alternativos" presentes na "relação construtiva" que, conforme o professor, conduz, observa, facilita o processo, dá a ele um direcionamento que favorece a (re)criação da relação professor-aluno.

Entretanto, embora o professor demonstre compreensão acerca da relevância do seu papel mediador na organização e no desenvolvimento 
do processo didático que ocorre no tutorial, ainda sente dificuldade em transpô-la para a prática. Das observações dos tutoriais foi possível identificar uma fragilidade da relação pedagógica construída no grupo tutorial: o domínio das discussões por alguns alunos, os quais, ao assumirem a exposição e a explicação do tema em estudo, de certa forma, ocupam o "lugar" do professor. Em um tutorial observado, uma estudante assume a liderança, registra no quadro branco uma célula para ilustrar sua explicação, sugere continuar falando acerca de morfologia, dirige-se ao professor para perguntar se devem discutir determinado aspecto, domina a "cena" o tutorial. O professor intervém apenas quando solicitado pelos estudantes, ou quando percebe que estão utilizando conceitos equivocados. Fora essas situações, ele observa atentamente e registra sem recorrer a mecanismos que incentivem a participação dos outros nove estudantes.

A centralidade do professor, característica de metodologias tradicionais é, nesse caso, transferida para alguns estudantes, enquanto outros não participam por não terem realizado o estudo individual dos pontos destacados nos objetivos de aprendizagem ou não terem desenvolvido algumas habilidades, como a de se expressarem oralmente, condição necessária à participação. Um desses estudantes recebeu a menção $\mathrm{MI}^{2}$ na ficha de avaliação diária de participação, denominada de "avaliação diagnóstica", por não ter evidenciado desempenho que indique o alcance dos objetivos de aprendizagem elaborados na sessão inicial para estudo do problema.

Esse relato evidencia, que a dinâmica do grupo tutorial pode funcionar muito bem para estudantes com autonomia acadêmica para estudar, pesquisar, realizar leituras orientadas ou não, que "aprenderam a aprender", lema difundido na legislação educacional brasileira e que caracteriza as metodologias ativas, orientadas pelos "princípios de individualização, liberdade e espontaneidade e, principalmente, de atividade, em que 'aprender fazendo' e 'aprender a aprender' estão sempre presentes” (VEIGA, 2014, p. 78). Para os que não "aprenderam a aprender", reproduz-se a passividade da aula clássica, focada na exposição do professor, só que agora o foco passa a

2 Média inferior correspondente à escala de 3,0 a 4,9 pontos na avaliação. 
ser em alguns alunos. Dessa forma, a preocupação com a aplicação de metodologias que coloquem os estudantes em atividade, com ênfase na assimilação de técnicas de como aprender, sobrepõe-se à necessária apropriação do conhecimento sistematizado por todos os estudantes.

$\mathrm{Na}$ análise de Araújo (2017), a centralização em um dos polos que envolve o processo ensino-aprendizagem, o aluno, compromete a estruturação adequada da aula, a exemplo da matriz tradicional, que tem como foco o protagonismo do professor, não leva em conta que a metodologia não pode ter um fim em si mesma, não pode se sobrepor ao estudante ou ao professor, mas deve se constituir como mediação entre o professor, o estudante e o conhecimento, assim como entre os próprios alunos. Esses aspectos caracterizam algumas fragilidades do tutorial no âmbito da PBL no curso de Medicina pesquisado.

No entanto, foi possível identificar nas observações dos tutoriais, potencialidades na aplicação da técnica no âmbito da PBL demarcadas pela relação democrática, pautada no respeito ao indivíduo, sendo o poder de decisão e ação compartilhado por todos. Algumas situações são bem representativas da relação estabelecida no grupo tutorial de fechamento do problema em estudo, com características inovadoras e emancipatórias, como a abertura dada pelo professor aos estudantes que desejavam aprofundar aspectos relacionados ao problema, não previstos pelo professor, indicando que o conhecimento não é trabalhado de forma circunscrita ao que o problema e os objetivos almejam em termos de aprendizagem, ele transcende, na medida do desejo e da curiosidade dos estudantes. Essa perspectiva contribui para a construção da autonomia acadêmica e pessoal do sujeito em formação, por meio do trabalho grupal e individual como consequência das relações estabelecidas no tutorial e da elaboração coletiva dos objetivos de aprendizagem, processo que imprime significado aos percursos formativos seguidos pelos estudantes.

Outra potencialidade observada nos tutoriais é a disposição do professor em sair da sua "zona de conforto", inter-relacionar os conhecimentos de sua área de formação e atuação, a enfermagem, a outras áreas de conhecimento necessárias ao estudo dos problemas, o que favorece aos 
discentes sua compreensão mais ampla e integrada. A fala do professor a seguir reforça o que foi possível observar na prática do tutorial.

Nas tutorias há um aspecto bem interessante que realmente se aplica à aprendizagem contínua, porque saímos do nosso estado confortável. Tive que aprender sobre outras disciplinas que estavam fora do escopo, saí da zona de conforto para entrar em outras áreas (Professor Henrique).

Embora não se possa afirmar que o professor Henrique trabalhe os conhecimentos ultrapassando os limites das disciplinas, uma das características do currículo integrado, segundo Bernstein (1977), ele busca estabelecer uma relação aberta entre os conhecimentos, podendo haver diferentes graus de integração, sendo os conteúdos subordinados a uma ideia central em permanente mudança - os problemas médicos discutidos no grupo tutorial.

\section{Considerações finais}

A formação de médicos com domínio de conhecimentos técnico-científicos, críticos, éticos e compromissados politicamente com a saúde individual e coletiva da população, na lógica do Sistema Único de Saúde (SUS), orientada para a humanização da Medicina, conforme indicam as Diretrizes Curriculares Nacionais do Curso de Graduação em Medicina (2014), pressupõe outra concepção de metodologia de ensino-aprendizagem. Uma metodologia que não cabe a polarização da relação pedagógica, ora no professor como na matriz pedagógico-metodológica tradicional, ora no estudante, conforme orienta a matriz escolanovista. Essa polarização representa um dilema para os docentes que buscam a superação de processos conservadores de ensinar, aprender, pesquisar e avaliar no ensino superior e para os estudantes que, mesmo conscientes e defensores do princípio básico da PBL e do grupo tutorial, de serem ativos na construção do conhecimento, oscilam ao questionarem a pouca intervenção do professor. 
Como alternativa superadora dessa polarização, a orientação é por uma metodologia colaborativa, participativa e problematizadora fundamentada na prática social em que professor e estudantes apesar de ocuparem posições distintas, constroem uma relação pedagógica favorável à compreensão e ao encaminhamento de soluções dos problemas apresentados pela prática social, a partir dos pressupostos da pedagogia histórico-crítica (SAVIANI, 2007). Nessa perspectiva, a atuação docente reveste-se de importância por ser ele o orientador da prática pedagógica que considera os condicionantes socioculturais que interferem na prática; a atuação do estudante também é relevante pois sem ele, não há processo didático. $\mathrm{Na}$ interlocução entre esses sujeitos, partindo da prática social, problematiza-se a realidade, articulando educação e sociedade, educação e política, educação e trabalho, conteúdo e metodologia, teoria e prática, objetivo e avaliação, sujeito e objeto do conhecimento.

A análise dos dados da pesquisa permitiu identificar alguns elementos constitutivos do grupo tutorial que sinalizam o movimento de transição da metodologia ativa para a pedagogia histórico-crítica, que são:

- O reconhecimento do docente acerca da importância do protagonismo dos estudantes no processo de ensino-aprendizagem, sem no entanto, abdicar de seu papel na condução desse processo;

- a compreensão pelo professor de que as metodologias que favorecem a participação dos estudantes num processo colaborativo, como a PBL, contribuem para a articulação teórico-prática em um módulo do curso essencialmente teórico;

- a compreensão pelos estudantes da necessária atuação e intervenção do professor no processo de discussão, problematização e análise dos problemas nos tutoriais para o alcance dos objetivos de aprendizagem, sem ferir os princípios da PBL;

- a prática social dos estudantes é determinante na realização do tutorial. É o ponto de partida na discussão dos problemas de estudo e o ponto de chegada, sendo transformada no desenvolvimento das etapas do grupo tutorial;

- a PBL preconiza a solução de problemas articulando-os aos conhecimentos técnico-científicos e ao contexto sociocultural, com foco 
na atenção à saúde individual e coletiva, enquanto o movimento da pedagogia ativa (escolanovista) discute os problemas de uma perspectiva interna da instituição educativa;

- o docente vivencia conflito epistemológico e metodológico manifestados pelo reconhecimento dos desafios de implementar metodologias participativas na formação de profissionais da saúde;

- o processo didático do grupo tutorial é planejado para problematizar, promover intercâmbios e a participação de alunos na construção do conhecimento.

Há urgência de mudanças conceituais mais abrangentes e profundas do ponto de vista metodológico no ensino superior articuladas ao movimento histórico da sociedade e da educação. A compreensão dessa premissa pelos colaboradores da pesquisa, articulada às práticas observadas no desenvolvimento do grupo tutorial no âmbito da PBL, reforçam a transição das metodologias ativas para as metodologias participativas, colaborativas e problematizadoras, fundamentadas na pedagogia histórico-crítica como possibilidade de se pensar e concretizar a formação de profissionais médicos socialmente comprometidos com a garantia dos direitos da população à saúde pública de qualidade.

\section{Referências}

ARAÚJO, J. C. S. Da metodologia ativa à metodologia participativa. In: VEIGA, I.P.A. et al. Técnicas de ensino e aprendizagem como expressão das metodologias problematizadoras "in press".

BARROWS, H. S. Criteria for analyzing a problems-based learning curriculum. In: RANKIN, J. A. (org.). Handbook on problem-based learning. Nova York: Forbes Custom Publishing, 1999.

BERBEL, N. A. N. A problematização e a aprendizagem baseada em problemas: diferentes termos ou diferentes caminhos? In: Interface - Comunicação, Saúde, Educação, v. 2, n. 2, 1998. 
BERNSTEIN, B. Clases, códigos y control. v. 2. Hacia una teoría de las transmisiones educativas. Madrid: Akal, 1977.

CONSELHO NACIONAL DE EDUCAÇÃO. Resolução CNE/CES n. 3, de 20 de julho de 2014. Diretrizes Curriculares Nacionais do Curso de Graduação em Medicina. (Diário Oficial, Brasília, 06/06/2014).

LEITINHO, M. C. e SÁ CARNEIRO, C. C. B. Aprendizagem baseada em problemas: Uma abordagem pedagógica e curricular. In: Veiga, I. P. A. (org.). Novas tramas para as técnicas de ensino e estudo. Campinas: Papirus, 2009.

SANTOS, B. S. Para uma pedagogia do conflito. In: SILVA; HERON, L. et al. (Orgs.). Novos mapas culturais, novas perspectivas educacionais. Petrópolis: Vozes, 1996.

SAVIANI, D. História das ideias pedagógicas no Brasil. Campinas: Autores Associados, 2007.

SAVIANI, D. A pedagogia no Brasil: História e teoria. Campinas: Autores Associados, 2008.

VEIGA, I. P. A. O cotidiano da aula universitária e as dimensões do projeto político-pedagógico. In: CASTANHO, S.; CASTANHO, M. E. (Orgs.). Temas e textos em metodologia do ensino superior. Campinas: Papirus, 2001.

VEIGA, I. P. A. Na sala de aula: O estudo dirigido. In: VEIGA, I. P. A. (org.). Técnicas de ensino: por que não? 21. ed. $4^{\mathrm{a}}$ reimp. Campinas: Papirus, 2014.

Recebido: 20/10/2016

Received: 10/20/2016

Aprovado: 20/11/2016

Approved: 11/20/2016 